\title{
Karakteristik Siyasah dalam al-Quran dan Hadis
}

\author{
Ilham Syukri' ${ }^{1}$, Agusri Fauzan ${ }^{2}$, Syahidin Syahidin ${ }^{3}$ \\ ${ }^{123}$ Institut Agama Islam Negeri Bengkulu \\ e-mail: ilhamsyukri@iainbengkulu.ac.id
}

\begin{abstract}
Abstrack
Al-Quran is a book in which it discusses the problems of the world and the hereafter. Understanding worldly concepts in al-Quran also requires a process of reasoning through the guidance of the Prophet's sunnah. One of the worldly problems mentioned in al-Quran is the political and ethical basics that must be adhered to in healthy politics in the style of al-Quran. Al-Quran is the principle of life, there is no single problem that exists in the world and even the hereafter unless it is regulated by the guidance and guidance of al-Quran and the valid sunnah, including in the world of politics, even the political character of al-Quran is not comparable. with it, everything is a benefit and blessing if it is used and understood by the right and proper individual. This research uses the thematic method (maudhu'i) about the siyasah verses. The results show that the political characteristics in al-Quran are 1. Bai'at, 2. Shura, 2. Responsibility, 3. Justice, 4. Silaturrahim. If these characters are applied, they will be safe in their career towards Allah SWT. On the contrary, if they do not disobey, they will be misled and get the wrath of the owner of the universe.
\end{abstract}

Keywords: Politics, Siyasah verse, Bai'at, Shura, equitable.

\begin{abstract}
Abstrak
Al-Quran adalah sebuah kitab yang di dalamnya membahas permasalahan dunia dan akhirat. Pemahaman konsep duniawi dalam al-Quran juga membutuhkan proses penalaran akal melalui bimbingan sunnah Nabi, sebagai sebuah otoritas resmi dalam memberikan penafsiran. Salah satu permasalahan duniawi yang disebut dalam al-Quran adalah dasar-dasar politik dan etika yang harus dipatuhi dalam berpolitik sehat ala al-Quran. Al-Quran itu adalah asas kehidupan, tidak ada satu permasalah pun yang ada diatas dunia bahkan akhirat kecuali sudah diatur oleh hidayah dan panduan al-Quran dan sunnah yang sahih, tak terkecuali dalam dunia politik, bahkan karakter politik al-Quran tak ada yang sebanding dengannya, semuanya membahwa manfaat dan keberkahan jika dipakai dan difahami oleh individu yang tepat dan pantas. Penelitian ini menggunakan dengan metode tematik (maudhu'i) tentang ayat-ayat siyasah. Hasil yang penelitian menunjukkan karakteristik politik dalam al-Quran adalah 1. Bai'at, 2. Syura, 2. Tanggung jawab, 3. Keadilan, 4. Silaturrahim. Karakterkarakter tersebut bila diaplikasikan maka akan selamat dalam karirnya menuju Allah swt, justru sebaliknya jika ia membangkang maka akan disesatkan dan mendapat murka dari pemilik alam semesta.
\end{abstract}

Kata Kunci: Politik, Ayat Siyasah, Bai'at, Syura, Adil

\section{Pendahuluan}

Sampai saat ini gerakan menjauhkan umat islam dari sumber utamanya semakin gencar dan agresif, baik melalui isu-isu yang miring tentang Islam atau berupa mengaburkan karakteristik ajaran Islam rahmatan lil 'alamin, seperti mengelabui identitas politik islam yang termaktub dalam AlQuran dan sunnah yang nota benenya sebagai petunjuk umat menuju peradaban dunia dan surga yang abadi di akhirat, 
ditambah lagi dengan tuduhan yang dialamatkan ke ajaran Islam yang dalam dugaan mereka hanya mengurus urusan akhirat saja padahal mereka lupa bahwa dalam al-quran dan sunnah mencangkup segalanya, agar umat manusia mencapai misi penciptaannya.

Beginilah kondisi umat Islam sepeninggalan sang pemimpinnya yang adil dan bijaksana, Rasul Muhammad SAW, hal ini pun sudah ada dalam sabda Rasul saw, bahwa hari semakin mendekati sore semakin rusak dan semakin nampak keburukannya, bahkan dalam sabda beliau umat Islam di akhir zaman tak ubahnya seperti buih yang lemah diombang-ambing oleh derasnya angin di lautan, jika kita teliti salah satu sebabnya adalah jauhnya manusia itu dari pemahaman Al-Quran dan sunah nabawiyah secara baik dan benar, dari pengetahuan politik yang sesungguhnya, jauhnya dari pemahaman Al-Quran dan Hadis rasul saw secara menyeluruh, maka dalam tulisan ini penulis akan memaparkan sedikit tentang Karakteristik Politik dalam Al-Quran, dengan harapan menjadikannnya sebagai lampu penerang dalam kondisi yang gelap gulita. Karena politik yang baik adalah bagian dari Islam, ajaran dunia akhirat, buktinya ibadah dalam islam bukan keperluan akhirat saja tapi untuk dunia juga, Semoga para pembaca bisa mengambil nilai-nilai agama dalam rangka menata dan memperbiki tatanan kehidupannya khususnya dalam berpolitik sehat, membangun dan beretika.

Dalam bahasa indonesia Politik, dalam bahasa arabnya disebut siyasah (السياسة) secara bahasa bermakna: pemerintahan, mengepalai, mengatur [melarangmemerintah] sebuah urusan ${ }^{1}$, mengayomi, melatih, mendidik, memelihara menjadikan sesuatu lebih baik $^{2}$, memperbaiki agar indah, memudahkan dan islah.

Dalam hadist nabi Saw3: إنَّ بَني إسرائيل كانت bahwa siasah disini bermakna para nabi diutus oleh Allah SWT kepada bani israil untuk mengatur-memimpin urusan mereka agar menjadi lebih baik dan tertata rapi.

Sedangkan dalam Al-Quran menurut penelitian kami tidak ada ayat yang secara jelas menyebutkan kata [shigot isim] siyasah tapi banyak akar kata ayat-ayat yang mengarah, mengacu dan menyinggung masalah siyasah seperti: sulthan [kekuasaan-hujjah-burhan], mulk

\footnotetext{
1 Fairuz Abadi, Qamus Muhit, (libanon: Muassasah al-Risalah, 2005). huruf sin hal. 781.

2 Sayyid Muhammad Azzubaidi, Qamus Taj 'Urus, (Kuwait: Hukumah Kuwait, 1965) jilid. 16 huruf sin, hal. 158.

3 Al-Bukhari, Shahih al-Bukhari, (Damaskus: Dar Ibnu Katsir, 2002) dalam kitab cerita para nabi, bab. informasi tentang bani israil, hadis no. 3455
} 
[raja-pemerintah-penguasa], hakim-hukumqadha' [keputusan], imarah [pemerintahan], ulil amri [pemerintah], khalifah-khilafah [pengatur-pejabat-pemimpin], imam [pemimpin, pemuka], daulah [negara], kendatipun demikian banyak kita dapatkan kata siyasah dalam perkataan sahabat dan tabi'in serta turast islam.

Jika ditinjau dalam pengertian para ulama klasik dan modern siyasah bermakna: sebuah ikhtiar dari pemangku kebijakan dalam rangka mengayomimengatur segenap hajad manusia dalam urusan dunia dan akhirat agar mencapai kesejahteraan dunia dan akhirat ${ }^{4}$.

Dari paparan di atas menjelaskan bahwa agama Islam dalam hal ini sumber utamanya al-quran dan sunnah sejak awal sudah hadir dalam mengatur dan memberi rambu-rambu siyasah agar umat manusia menjadi bermartabat didunia dan akhirat, kalo kita tela'ah lebih jauh lagi siyasah dalam agama islam memiliki sisi keunikan dan perbedaan dengan siyasah manusia pada umumnya.

\section{Pembahasan}

\section{Bai'at}

Karakteristik Bai'at Nabawiyah dalam Al-Quran yaitu Bai'at manhaj ilahiyah bukan taqlid bid'ah dhalalah, maksudnya

4 Lajnah, Ensiklopedia Ilmu Siyasah, (Kuwait: Univ Kuwait, 2010), hal. 102. adalah diantara karakteristik siyasah Islam adalah ikrar suci, janji setia dari orang-orang yang telah beriman kepada Nabi Saw [termasuk yang memiliki posisi pengganti Nabi Saw], untuk menolong agama Islam dari ancaman dalam dan luar, kesetiaan itu mereka pertahankan kendatipun nyawa sebagai taruhannya, siyasah ini ada sunnahnya didalam AlQuran dengan dalil bahwa Rasul Saw, itu diutus oleh Allah swt posisinya sebagai saksi bagi umat manusia tentang ajaran yang dibawanya, sebagai pemberi kabar gembira dan pertakut agar manusia setia mengikuti ajarannya, tentu saja dakwah mulia ini akan mendapat respon negatif dan teror dari musuh-musuhnya oleh karena itu kewajiban orang-orang yang telah beriman kepada Nabi Saw adalah menolongnya, membelanya, memuliakannya serta mencintainya saat suka dan duka, dalam kondisi hidup dan mati yang dimulai dengan Sunnah bai' at ini ${ }^{5}$.

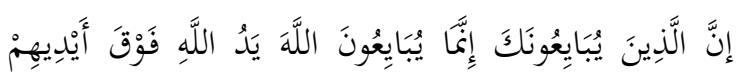

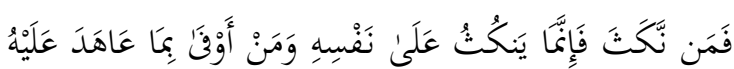<smiles>CCC[As]=[As]C</smiles>

Bahwasanya orang-orang yang bersumpah setia kepada kamu sesungguhnya mereka bersumpah setia kepada Allah. Kekuasaan Allah di atas kekuasaan mereka, maka barangsiapa yang melanggar janjinya niscaya

${ }^{5}$ Q.S. al-Fath ayat: 9

${ }^{6}$ Q.S. al-Fath ayat: 10 
akibat ia melanggar janji itu akan menimpa dirinya sendiri dan barang siapa menepati janjinya kepada Allah maka Allah akan memberinya pahala yang besar.

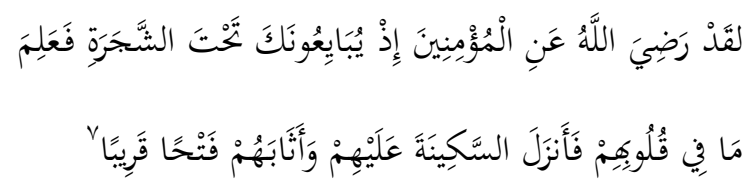

Sesungguhnya Allah telah ridha terhadap orang-orang mukmin ketika mereka berjanji setia kepadamu di bawah pohon, maka Allah mengetahui apa yang ada dalam hati mereka lalu menurunkan ketenangan atas mereka dan memberi balasan kepada mereka dengan kemenangan yang dekat (waktunya).

Dua Ayat dalam surah al-fath [madaniyah] ini menjelaskan bahwa Allah Swt, meridhai para sahabat Nabi Saw [yang berjumlah 1400 orang], yang setia lagi ikhlas untuk ikut serta berbai'at kepada beliau dalam peristiwa hudaibiah di bawah pohon samurah. Ketika itu para sahabat menyatakan janji setia kepada Rasul Saw, yang pada hakikatnya adalah janji setia kepada Allah, ta'at kepada rasul karena perintah Allah Swt, untuk mengabdi kepada Allah dan Rasul-Nya ${ }^{8}$

Dalam dua ayat ini ada banyak hal yang dapat kita petik khususnya tentang karakter siyasah islam diantaranya adalah:

- Dalam bai'at $^{9}$ ridwan di hudaibiyah dibawah pohon

\footnotetext{
${ }^{7}$ Q.S. al-Fath ayat: 18

8 Imam Baidhowi, Anwarut Tanzil wa Asraru alTakwil, (Beirut: Dar shadir, 2001), 2/994.

'Bai'at adalah usaha [akad-transaksi] untuk bergabung dalam satu komitmen dan perjuangan untuk menggapai sebuah tujuan yang baik dan terpuji. Maksud
}

samurah ini mengajarkan kita tentang karakteristik siyasah islam yaitu: tujuan utama dalam siyasah adalah meraih redho Allah swt, bukan karena ingin mewujudkan keinginan Nabi, bukan tujuan yang lain kecuali hanya mengenalkan manusia kepada penciptanya, bukan untuk tujuan duniawi tapi ukhrawi ${ }^{10}$, dengan kebersamaan dalam suka dan duka, senasib dan sepenanggungan dalam menggapai tujuan yang mulia yaitu pahala dari Allah swt, dan dengan sarana yang terpuji yaitu persatuan disaat susah dan senang, mengedepankan keharmonisan dalam hal apapun, siap menghadapi segala resiko kehidupan dengan modal redo Allah dan keta'atan kepadanya, sangat jelas sekali ketika diplomat Rasul saw, usman bin affan masih ditahan dimakkah dan di kabarkan sudah dibunuh oleh orang musrik disana, dengan spontan rasul dan para sahabat membela usman bin affan dalam suka dan duka, maka dengan hati yang tulus dan keimanan yang kuat mereka

bai'at disini adalah hanya dalam ketaatan dan kepatuhan kepada Allah swt dan rasulNya.

${ }^{10}$ Lihat isi bai'at aqabah satu dan dua. 
menyatukan tangan dan hatinya untuk membela usman bin affan ${ }^{11}$ yang sebelumnya telah membuktikan pula kesetiaan dan ketulusannya kepada Nabi muhammad saw.

- Karakter siyasah Islam adalah berani membela dan berjuang untuk mewujudkan kebenaran, keadilan karena keyakinan yang kuat kepada Allah swt, sehingga dengan dasar keimanan yang kokoh inilah, segala aktifitas siyasah memberi dampak yang baik dan mensejahterakan, tanpa ada kerusakan dan kerugian dipihak manapun, dalam hal ini usman bin affan diutus baginda Nabi ke mekah untuk menyampaikan bahwa keinginan beliau berkunjung kesana dalam rangka mengagungkan kota suci dan beribadah kepada Allah swt, sebuah tujuan yang mulia dan maksud yang terpuji, sekali-kali bukan untuk berperang dan balas dendam seperti yang mereka duga, namun disambut dengan kedengkian dan permusuhan dari kaum kafir quaraish ${ }^{12}$.

11 Abu Lais Samarqandi, Tafsir Bahrul 'Ulum, (Beirut: Dar Kutub Ilmiyah, 1993), 256.

12 Imam Abi Su'ud, Tafsir Irsyad 'Aqlussalim, (Lebanon: Dar Risalah, 2012), 2/27.
- Karakter siyasah Islam adalah wasathan, moderat ${ }^{13}$, bermanfaat timbal balik, tidak melampau batas, senantiasa berada dalam keseimbangan dalam hal apapun dibidang apapun, ia seimbang antara kepentingan lahir dan bathin, stabil antara ucapan dan hati, sisi dunia dan akhirat, kebutuhan materi dan non materi terlihat jelas dari sikap para sahabat yang diredoi oleh Allah swt itu, karena selaras sikap dan hatinya dalam keta'atan dan patuh kepada perintah Nabi Saw yang pada hakikatnya ta'at kepada Allah swt dalam janji mereka pertama kali14, terlihat juga kesuksesan mereka mendapat ganjaran materi dan non materi dari Allah swt [ridho Allah swt dan kemenangan khaibar].

\section{Syura}

Karakteristik Syura dalam al-Quran yaitu musyawarah mencari maslahah bukan demokrasi voting. Maknanya adalah yang membedakan siyasah Islam itu dengan yang lain keunikannya pada

13 Bermakna adil, pertengahan, tidak berat sebelah, tidak kurang satu apapun.

14 Abdurrahman bin Hasan, Tafsir al-Mubin, (Riyadh: Dar Tadmir, 1429 H), 4/200. Lihat Juga surah al'Araf ayat: 172 tentang janji setia dan patuh kepada Allah swt saat di ucapkan petama kalinya. 
urusan syura, ia murni bahasa dan istilah al-Quran yang tidak dikenal lafaz dan maksudnya kecuali setelah di turunkannya Al-Quran, asalnya bermakna mengemukakan sesuatu pendapat dan menampakkannya, dan [ وأخخ [الشيئ yaitu aktifitas bermusyawarah bertukar pendapat dari ahli dan pakarnya $^{15}$ yang bertujuan ganda disamping mendapatkan-mengambil keputusan yang terbaik [أصلح], layak sesuai sikon juga sebagai penghindar perpecahan dan permusuhan, hal semacam ini tidak ada dalam demokrasi barat, voting yang praktek dan tujuannya untuk kemaslahatan dunia saja, kadang kala menindas dan memaksa pendapat kepada kelompok minoritas, sedangkan dalam syura ada prinsip keadilan, kebenaran serta tanggung jawab kepada Allah Swt dan sosial secara seimbang kendatipun hanya disampaikan atau didukung oleh satu orang saja namun tetap wajib diaplikasikan.

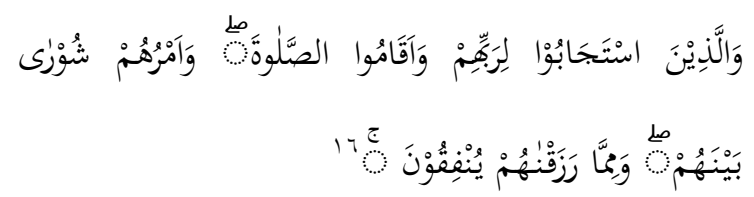

Dan (bagi) orang-orang yang menerima (mematuhi) seruan Tuhan dan melaksanakan

15 Maksudnya adalah syarat dari musyawarah itu haruslah wajib hadir para pakar dan ahlinya yang sifat, karakternya rekam jejaknya baik, lihat surah al-Nisa' ayat: 83 dan surah al-Zumar ayat: 9 .

${ }^{16}$ Q.S: al-Syura ayat: 38 salat, sedang urusan mereka (diputuskan) dengan syura [musyawarah] antara mereka; dan mereka menginfakkan sebagian dari rezeki yang Kami berikan kepada mereka.

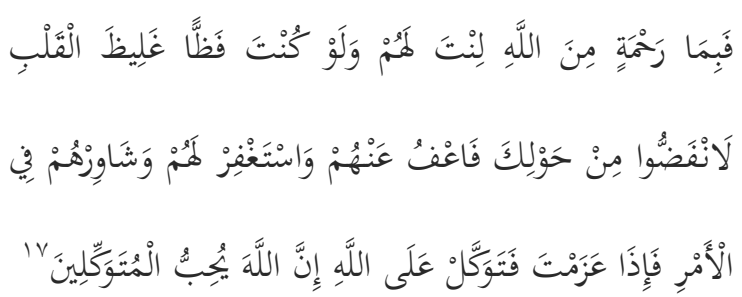

Maka disebabkan rahmat dari Allah-lah kamu berlaku lemah lembut terhadap mereka. Sekiranya kamu bersikap keras lagi berhati kasar, tentulah mereka menjauhkan diri dari sekelilingmu. Karena itu maafkanlah mereka, mohonkanlah ampun bagi mereka, dan bermusyawaratlah dengan mereka dalam urusan itu. Kemudian apabila kamu telah membulatkan tekad, maka bertawakkallah kepada Allah. Sesungguhnya Allah menyukai orang-orang yang bertawakkal kepada-Nya.

Ayat pertama menjelaskan kewajiban negara untuk mengikut sertakan rakyat dalam mengambil keputusan, tidak membeda-bedakan mereka dalam hal keikutsertaan itu, ayat yang kedua menjelaskan bahwa musyawarah adalah sunnah yang wajib dipegang oleh generasi setelah Rasul saw, dalam menetapkan pondasi-pondasi keputusan ditengah masyarakat, inilah intisari kehadiran syura18.

Musyawarah menempati posisi yang strategis dalam pondasi agama islam, ia memegang kendali agama setelah

\footnotetext{
${ }^{17}$ Q.S: Ali Imran ayat:159

18 Shafiyyurrahman Mubarak Furi, Ahzab Siyasiyah fi al-Islam, (Kairo: Dar Subul Mukmininin, 2012), 83.
} 
iman kepada Allah swt, ta'at kepada Rasul Saw, perintah sholat dan jihad, maknanya adalah menyia-nyiakan syura efeknya seperti menyia-nyiakan tauhid, ibadah sholat, dan zakat inilah karakter siyasah musyawarah dalam islam, tidak bisa dipisahkan dari sendi-sendi agama, selagi umat islam meremehkan sholat, zakat maka jangan harap konsep dan hakikat musyawarah bisa diterapkan dengan baik.

Musyawarah dalam islam bukan sekedar memilih keputusan yang paling tepat dari yang tepat, terbaik dari yang baik atau mengambil keputusan yang lebih sedikit resiko dan mudaratnya, namun jauh dari itu, ia sebagai perekat persatuan pengikat persaudaraan yang pada hakikatnya sebagai minhah ilahiah [bonus dari Allah] semenjak penciptaan adam, ketika Allah swt berfirman kepada Malaikat bahwanya, Dia menciptakan manusia sebagai khalifah di bumi ini, disisi lain musyawarah sebagai lambang kasih sayang, penghormatan dari pemimpin kepada yang dipimpin, dan sekaligus sebagai bukti keharmonisan dalam suatu masyarakat itu sendiri, jika tidak ada syura maka tidak ada saling menghargai dan saling menghormati, terlihat jelas pada ayat: 159 surah ali imran, begitu kecintaan dan kasih sayang Nabi Saw kepada sahabatnya, sehingga beliau diperintahkan untuk bermusya- warah dengan sahabatnya dalam urusanurusan yang sifatnya sosial dan masyarakat, urusan yang tidak berhubugan dengan agama dan syari'at ${ }^{19}$.

\section{Keadilan}

Karakteristik keadilan dalam al-quran menegakkan sendi-sendinya bukan meruntuh bangunannya. Maknanya adalah karakteristik siyasah Islam ada pada pilar keadilan ${ }^{20}$ yang menjadi tujuan utamanya, disitulah kemulian dan kehormatan manusia sebagai makhluq Allah swt, bahkan dengan keadilan itulah diturnkannya kitab suci pedoman hidup, dengan keadilan jualah diutus para nabi dan rasul, dengannya pula berdirinya sistem alam raya ${ }^{21}$, bahkan sangat dijunjung tinggi nilai dan kedudukannya karena dengan keadilan bumi menjadi berkah, makhluk menjadi damai, nyaman dan sentosa, dengan siyasah keadilan inilah sebuah keluarga, masyarakat dang bangsa menemukan kesucian dan jati diri dan harkat martabatnya sebagai makhluk Allah swt, Al-quran menyebutkan bahwa manusia sama dalam hal penciptaan dari

\footnotetext{
19 Imam Fakhrurrazi, Tafsir Kabir, (Libanon: Dar al-Fikr, 1981), 159.

20 Adil disini dalam artian tidak menzolimi, senantiasa berada dalam ranah kebenaran, samaseimbang-selaras-sepadan antara mendapatkan hak dan menunaikan kewajiban dan Perhatian Terhadap Hak-Hak Individu dan Memberikan Hak-Hak Itu kepada Setiap Pemiliknya.

21 Yusuf al-Qaradhawi, Malamih Mujtama' Muslim Kama Nansyuduha (Kairo, Maktabah Wahbah, 2013), 68.
} 
manusia yang satu yaitu adam tidak ada beda, hanya yang membedakan adalah ketaatan dan kepatuhan dia dalam beribadah dan beramal diatas dunia ini,
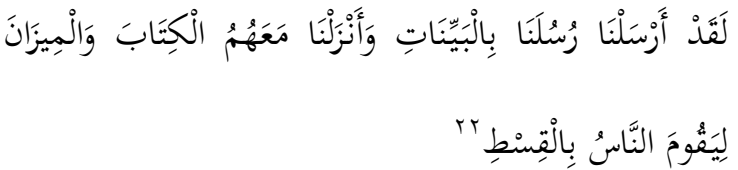

Sesungguhnya Kami telah mengutus rasulrasul Kami dengan membawa bukti-bukti yang nyata dan telah Kami turunkan bersama mereka al-Kitab dan mizan (neraca, keadilan) supaya manusia dapat melaksanakan keadilan.

Sangat jelas bahwa ada korelasi yang erat antara kehadiran utusan Allah swt yaitu para nabi dan rasul yang dibekali dengan penjelasan, mukjizat dan keterangan yang nyata, dengan kehadiran pedoman utama yaitu kitab sebagai landasan aktivitas manusia dan kehadiran pilar keadilan [sebab-sebab keadilan] dan kebenaran karena Allah ingin tegaknya keadilan bagi seluruh manusia23, dapat kita petik disini sebagaimana yang disebutkan oleh imam al-alusi dalam tafsirnya ${ }^{24}$ bahwa keadilan disini berlaku ganda, mencangkup sosial masyarakat dilakukan dengan seimbang dalam takaran dan timbangan, dan pada urusan akhirat dengan mengaplikasikan ajaran kitabNya, sehingga adil dalam teori dan prakteknya.

22 Surah al-Hadid ayat:25

23 Ibnu Katsir, Tafsir al-Quran al-'Azim, (Saudi: Dar Thibah, 1999), 25.

24 Tafsir surah al-Hadid ayat:25

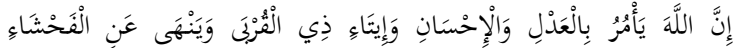

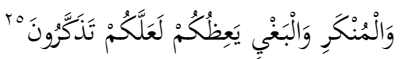

Sesungguhnya Allah menyuruh (kamu) berlaku adil dan berbuat kebajikan, memberi kepada kaum kerabat, dan Allah melarang dari perbuatan keji, kemungkaran dan permusuhan. Dia memberi pengajaran kepadamu agar kamu dapat mengambil pelajaran.

Perhatikanlah ayat ini $^{26}$ sehingga jelas karakter siyasah islam, adil kepada lawan dan kawan, adil atas dasar perintah Allah swt, adil yang tidak dipengaruhi oleh hal dan keadaan, sebagaimana ungkapan syaihul mufassirin, imam Thabari dalam tafsirnya: Allah swt menyuruh engkau wahai Muhammad didalam Al-Quran untuk berlaku adil dalam makna inshaf yaitu kamu mengakui, menyadari sepenuh jiwa dan ragamu bahwa nikmat yang ada padamu [memimpin dan dipimpin] adalah pemberian Allah swt semata, lalu penuhi nikmat itu dengan bersyukur [beriman dan beramal sholeh] karena Dia pemiliknya, itulah makna adil disini. Artinya dalam siyasah islam konsep ketuhanan-konsep kenabian-konsep interaksi kemasyarakatan adalah hal utama yang tidak bisa dipisahkan antara ketiganya, yang diperintahkan oleh Allah

\footnotetext{
${ }^{25}$ Surah al-Nahl ayat: 90

26 Secara umum ayat ini menjelaskan perintah wajib menegakkan siyasah Keadilan, moderasi dalam segala hal, Ihsan kepada makhluq Allah, Takaful, kebersamaan sesama makhluq sosial.
} 
swt disini adalah strategi membangun jiwa raga dengan siyasah keadilankebaikan-persamaan yang mengacu pada stadar Allah swt, bukan pada yang lain yang dicampuri oleh kepentingan dan kehendak hawa nafsu duniawi belaka, inilah karakteristik dari Allah-dengan izin Allah dan akan kembali segala urusan hanya kepada Allah swt.

Sementara Syaikh Sya'rawi rahimahullah mengatakan bahwa ayat ini adalah ayat yang paling mencangkup urusan siyasah kebaikan dan nilai keutamaan, mengandung tiga perintah dan tiga larangan, ayat yang diyakini oleh orang quraish sebagai intisari kebaikan bahkan sekaliber ikrimah anak abu jahal dan walid bin mughirah pun mengakui dan salut kepada ayat ini sebagai karekteristik siyasah dakwah nabi Saw, lebih lanjut beliau mengatakan bahwa makna adil disini adalah ketepatan, kesamaan, tidak berat sebelah, tidak merugikan sisi lain, sehingga ia bisa berjalan lurus mencapai tujuan, maka untuk mewujudkan keadilan dalam islam dalam segala hal [akidah, ibadah, mu'amalah-urusan dunia dan hal-hal yang menyangkut akhirat] maka Allah swt bentuk siyasah takaran dan timbangan ${ }^{27}$.

27 Muhamad Mutawaly Sa'rawi, Khawatir AlQuran, (Kairo: El-Akbar Yaum, 2001), 13/445.

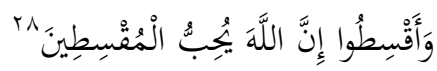

"Dan berbuat adillah, sesungguhnya Allah mencintai orang-orang yang berbuat adil.

Maksudnya adalah kewajiban berlaku adil dalam setiap lini kehidupan, karena Allah swt hanya meridhoi orangorang yang berprilaku adil.

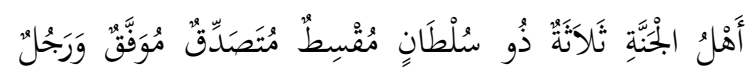

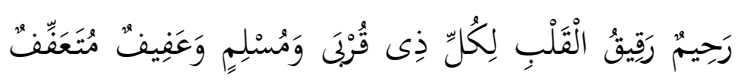<smiles>[As]=[As]</smiles>

(Diantara) penghuni surga ialah tiga orang; seorang penguasa yang adil, serta ahli sedekah dan mendapat bimbingan dari Allah; orang yang memiliki sifat penyayang dan lembut hati kepada keluarga dekatnya dan setiap kepada muslim serta orang yang tidak mau memintaminta sementara ia menanggung beban keluarga yang banyak jumlahnya.

Makna hadist ini sebagaimana yang difahami oleh para ulama adalah sifat atau kriteria penduduk surga setidaknya ada tiga karakter: Yang pertama ذُو سُْلَْانٍ مُعْسِطُ

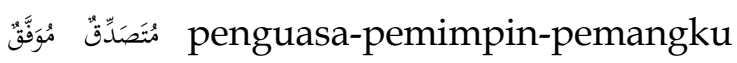
roda pemerintahan yang mampu berlaku adil, bijaksana kepada masyarakatnya, bahkan bukan hanya sekedar ituia pun bersikap dermawan secara adil, banyak kebaikan dan keberkahan pada rakyatnya, gemar bersedekah, memimpinsesuai syari'at Allah swt, pada akhirnya

\footnotetext{
28 Surah al-Hujurat ayat: 9

29 Muslim ibn Hajjaj al-Qusyairi al-Naysaburi, Shahih Muslim, (Saudi: Dar Thibah, 2006), 2865.
} 
disayang Allah dicintai manusia. Yang

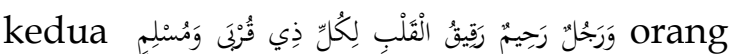
yang memiliki rasa kasih sayang dihati sanubarinya terhadap sesama, berhati lembut, terenyuh untuk membantu keluarga dan masyarakat luas, bisa juga bermakna orang yang gemar memberi ma'af dan senantiasa memohon ampun

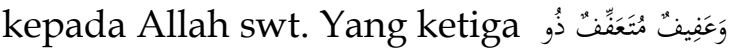
عِيَّ orang yang diuji dengan keterbatasan namun ia mampu menjaga dirinya dari hal yang merendahkan harga diri dan martabatnya sebagai hamba Allah swt, dalam bahasa lain seorang yang miskin namun bisa seimbang sabar dan syukurnya, mampu ikhtiar dan tawakkal walaupun dihimpit oleh permasalahan ekonomi.

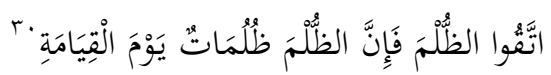

"Takutlah berbuat zhalim karena sungguh ia mendatangkan kegelapan-kegelapan di hari Kiamat.

Hadis ini menguatkan karakter siyasah Islam yang mengusung ajaran bahwa zhalim adalah sikap yang bertentangan dengan nurani kemanusiaan, sehingga tidak dikenal dalam kamus ajaran siyasah Islam satu prinsip pun yang mengandung aniaya, merusak, melampaui batas, mengambil milik orang lain, salah menempatkan sesuatu, memusuhi, merugikan segala pihak, dan hal-hal yang menimbulkan benci dan dendam.

\section{Tanggung Jawab}

Karakteristik tanggung jawab dalam al-Quran sebuah kebebasan yang dibatasi dengan syari'at bukan keinginan hawa nafsu. Islam adalah agama yang menjamin keselamatan dunia maupun akhirat selagi kita patuh dan tunduk dengan ajaranNya, namun jika kita mengambilnya sebagian dan membuangnya sebagian, atau melupakan sama sekali aturan Allah swt itu maka petakalah yang akan terjadi, inilah hukum Allah swt yang tetap berlaku kepada siapa saja, dalam siyasah islam siapapun bebas memilih, bebas menentukan pilihan, baik itu skala individu maupun sosial, dalam hal berpendapat bahkan dalam memilih agama sekalipun tidak ada paksaan dari Allah swt, karena dasar dari keimanan dan kewajiban adalah kebebasan memilih dan bersikap. Namun yang harus kita fahami dengan baik adalah karakter siyasah Islam itu sendiri dalam konteks merawat dan menata ruang kebebasan mestilah mengikuti syari'at ilahi, semuanya akan diminta pertanggung jawabannya di akhirat kelak, karenanya berhati-hatilah dalam menggunakan 
kebebasan itu dalam memilih pilihan anda. ${ }^{31}$

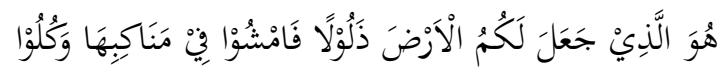

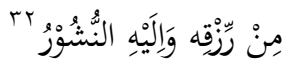

Dialah yang menjadikan bumi itu mudah bagi kamu untuk dihuni, Maka berjalanlah di segala penjurunya dan makanlah sebahagian dari rezki-Nya. dan hanya kepada-Nya-lah kamu (kembali setelah) dibangkitkan.

Ada beberapa hal yang mesti kita ingat dalam ayat ini: yang pertama sejak dari mulanya bumi ini sebagai hadiah dari Allah swt untuk kemaslahatan manusia agar bisa sukses di dunia dan di akhirat, yang kedua bekerjalah semasa didunia karena iman dan amal itulah yang akan dibawa ke akhirat, yang ketiga jadikan akhirat urutan pertama, jika tidak demikian maka hidup kita tak ada makna, yang keempat kebebasan yang Allah swt berikan kepada manusia untuk beraktifitas, bersiyasah, makan, minum dan yang lain-lain hendaklah dikunci dengan kata terakhir dan kata awal dalam ayat ini, yaitu hanya kepada Allah kamu kembali dan mempertanggungjawabkan segala aktifitas kebebasannya dimuka bumi ini, dan ingat ayat pertama bahwa Dia, Allah Swt, yang telah memberikan

\footnotetext{
31 Yovenska, L., and Olan Darmadi. "Karakteristik Pemimpin dalam Islam." AL IMARAH: JURNAL PEMERINTAHAN DAN POLITIK ISLAM 4.2 (2019): 150-162.

32 Surah al-Mulk ayat: 15
}

kesempatan kepada kamu sehingga bisa hadir didunia ini, maka berupayalah bersyukur kepadaNya33 dan jangan lari dari keinginanNya, betapapun jua kelak kamu pasti dihisab dab diproses didepan Allah swt. ${ }^{34}$

Dalam konteks kebebasan Al-Quran senantiasa mengingatkan kita bahwa ia adalah amanah, sekaligus sebagai ujian Tanggung jawab manusia dihadapan Allah swt karena Ia telah menciptakan manusia dalam bentuk yang sebaikbaiknya, dimuliakan pula dengan berbagai kemuliaan mulai dari ditiupkannya ruh, sampai iblis dan malaikatpun disuruh bersujud kepada manusia, lalu diberi pula nikmat yang banyak, rezeki yang berlimpah, yang tak kalah pentingnya lagi nikmat ilmu dan akal sehat hidup dibumi yang luas sebagai modal untuk melakukan kewajiban kepada Allah swt. Lalu Apa tujuannya?. Agar ia tau dan mengetahui siap dirinya, Agar menjalani tugas dengan baik, Supaya menghadap-ta'at kepada Allah dengan baik, Agar mencari akhirat, Agar melaksanakan tanggung jawab, Agar manusia bermanfa' at bagi yang orang lain, Agar ia memakmurkan bumi dengan baik, Agar mencari keridhoan Allah.

\footnotetext{
${ }^{33}$ Abi Su'ud, Tafsir Irsyad 'Aqlussalim, (Lebanon, Dar Risalah, 2012), 3/56.

34 Abdul Kadir Maghribi, Tafsir Juz Tabaraka, (Kairo: Matba'ah Amirah, 1947), 27.
} 


\section{Silaturahim}

Karakteristik silaturahim dalam alquran, menjalin komunikasi merawat generasi, bukan menebar pesona dan menimbulkan kerusakan. Maksud pernyataan ini adalah siyasah islam selalu dilandasi dengan maksud yang mulia dan cara yang baik, salah satunya adalah silaturahim dalam makna yang sebenarnya bukan seperti yang diduga oleh sebagian mereka yang mengatakan bahwa silaturahim itu bentuknya blusukan dan memberi bantuan saja, tapi jika merujuk pada Kamus Besar Bahasa Indonesia silaturahim atau silaturahmi bermakna tali persahabatan atau persaudaraan, maknanya dalam istilah Alquran adalah merawat iman ${ }^{35}$ dengan menyambungkan kasih-sayang atau kekerabatan yang menghendaki kebaikan, bisa kita simpulkan bahwa hakikat silaturahim: Menebar kasih sayang antar keluarga, menghubungkan yang terputusmerapatkan yang renggang-mendekatkan yang jauh-memberi meskipun pernah dihalangi-mema'afkan walaupun orang lain menyakiti kita, bahkan dalam sabda Rasul Saw dinyatakan bahwa:

ليس الواصل بالمكافئ، ولكن الواصل الذي إذا قطعت رحمه وصلها -يا عقبة بن عامر، صل من قطعك، وأعط من لون

35 Bahkan dalam Islam sillah sebagai tanda dari keimanan seseorang
حرمك، واعف عمن ظلمك، - وادفع السيئة بالحسنة، قال تعالى: إن الحسنات يذهبن السيئات -من جاء بالحسنة فله

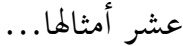

Penjelasan: pemahaman silaturahim itu ada 3 tingkatannya: yang pertama: washil [menjalin], yang kedua: mukhafi' [membalas setimpal], yang ketiga: washil qati'[menyambung yang terputus], ia bukan hanya sekedar kegiatan kunjungmengunjungi, saling bertegur sapa, saling menolong, dan saling berbuat kebaikan, saling berbalasan salam, berjabat tangan atau memohon maaf, saling nasehatmenasehati, memberi sebab hadiyah, menolak kezaliman, menebarkan senyum, do'a untuk sesama. Intinya menginginkan kebaikan bagi orang lain siapapun dia, seperti dirinya sendiri.

Jika kita perhatikan ayat-ayat Alquran yang memaparkan silaturahim, senantiasa identik dengan mengandengkan kata rusak sebagai akibat dari silaturahim yang gagal dan cacat dalam pelaksanaannya, seperti dalam surah alBaqarah ayat: 27, dan surah muhammad ayat: 22 , sedangkan dalam al-Ra'du ayat: 21, silaturahim digandengkan dengan orang yang memuliakan tuhannya dan takut kepada siksa-Nya, dan dalam surah al-Nisa' ayat: 1 ia digandengkan dengan perintah bertaqwa kepada Allah swt. 


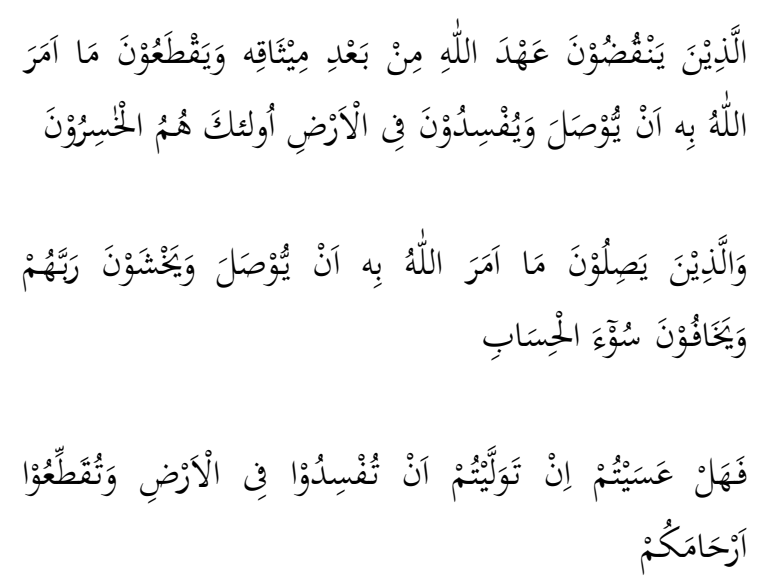

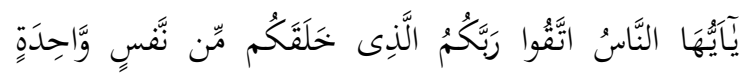

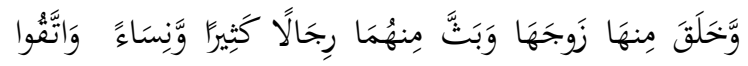

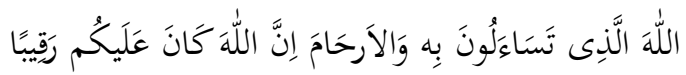
Dalam agama Islam siyasah silaturahim ini bukan hanya sekedar sarana mendekatkan diri dengan orang lain, dengan cara datang dan memberi apa yang kita miliki, tetapi teori dan pelaksanaannya jauh lebih mulia dari itu semua, ia sebaga rangkaian penting dalam ibadah dan ubudiyah kepada Allah swt, semakin memberi manfaat dan bekas kebaikan kepada orang lain lewat relasi yang ia bangun maka, semakin bagus ubudiyahnya kepada Allah swt, para pakar mengatakan bahwa silaturahim dalam pemahaman agama islam selalu meninggalkan bekas dan pengaruh yang positif, baik sifatnya menjaga tatanan internal dan menjaga stabilitas eksternal, karena padanya unsur kepekaan sosial, keamanan, termasuk kestabilan ekonomi dan politik ${ }^{36}$, diantara faedahnya jika dilakukan dengan penuh keikhlasan dan tanpa pamrih, adalah sebagai berikut:

Ditambahkan dan diberkahi rezekinya أن يُبنسَطَ له في رزقه, maknanya adalah Rezeki itu umum bukan hanya sekedar uang dan materi, namun semua pemberian yang bermanfa'at adalah rizki, puncak dari rizki itu kedekatan dengan Allah swt, saat hamba mengenal dan ta'at kepada Allah swt itu rezeki yang paling berharga. Para pakar hadist memahami sementara Maksud kalimat melapangkan [rezekinya], lancar usahanya mudah urusannya, semakin sukses, bisnisnya bisa semakin lancar, grafik rezekinya selalu naik, pelangganya makin banyak, angsurannya lancar, harta kekayaannya melimpah, beban hidup jadi ringan, para ulama yang lain juga memahami maknya adalah Diberkahi rizkinya menjadi sarana dalam melakukan amal shaleh, cerita keberkahan, Dihindarkan dari bahaya malapetaka dunia, silaturahim bisa mengatasi persolan hidup: seperti menemukan jodoh yang baik lewat silaturahim, bisa mendapatkan keturunan bagi yang sulit hamil, bisa teratasi masalah bathin, himpitan hidup, Solusi keuangan keluarga.

\footnotetext{
36 Muhammad Mahmud, Silatul Arham, Waahkamul Khas biha fi Fighil Islami, (Libanon: Dar Basyair Islamiyah, 2011), 84.
} 
Dipanjangkan umurnya (ينشأ له في أثره) maksudnya adalah: ditambah keberkahan umurnya dan dimudahkan dan dibimbing untuk beribadah sebelum meninggal dunia, waktunya berkah, hidupnya berkah sehingga bisa beribadah didunia dan bermanfaat di akhirat, alhasil umurnya berkwalitas dan tidak sia-sia, terhindar dari berbuat dosa sebab silaturahim yang dia lakukan. Ada juga ulama berpendapat maksudnya adalah ditunda kematiannya karena taqdir Allah yang bersifat mu'allaq. Ada juga yang mengatakan bahwa akan dikaruniai keturunan yang baik, yang sholeh atau sebutan yang baik diabadikan sepanjang masa. ${ }^{37}$

Dihindari dari kematian yang buruk, su'ul khatimah (ويدفع عنه ميتة السوء) maknanya adalah ia terhindar dari kesusahan saat berpisah dengan dunia, ada orang yang sakratul mautnya disiksa oleh Allah lagi dilaknat mereka itu seperti matinya orang kafir, orang yang banyak dosanya, banyak kemaksiatannya, menzolimi orang lain dan akhirnya masuk api neraka ada orang yang meninggal dengan mudah dan tenang, damai itulah meninggalnya orang yang menjalin silaturahim, hidup tenang mati pun dalam keadaan santai.

37 Zulfikar, Eko. "Tradisi Halal Bihalal dalam Perspektif Al-Qurân dan Hadis." Jurnal Studi AlQur'an 14.2 (2018): 127-150.

\section{Kesimpulan}

Maka dari penjelasan diatas dapat kita petik kesimpulan bahwasannya: Siyasah jika dibawa keranah agama, jika diarahkan oleh agama, jika berlandaskan agama akan bermakana: Adil dalam memimpin, makmur, sejahtera dalam kehidupan, berpihak kepada rakyat kecil, membantu orang yang teraniaya, memberikan peluang yang sama rata kepada masyarakat dalam kehidupan ini, agama itu membawa pengaruh baik terhadap siyasah bahkan menjadikannya lebih baik, dan lebih bermakna terarah dan sukses dunia akhirat, namun kedangkalan pengetahuan dan kerdilnya imanlah yang mengatakan bahwa agama tidak berhubungan dengan siyasah. Hasil yang penelitian menunjukkan karakteristik politik dalam al-Quran dan hadis adalah 1. Bai'at, 2. Syura, 2. Tanggung jawab, 3. Keadilan, 4. Silaturrahim. Karakter-karakter tersebut bila diaplikasikan maka akan selamat dalam karirnya menuju Allah swt, justru sebaliknya jika ia membangkang maka akan disesatkan dan mendapat murka dari pemilik alam semesta.

\section{Referensi}

1. Abu Lais Samarqandi, Tafsir Bahrul 'Ulum, (Beirut: Dar Kutub Ilmiyah, 1993), 256 
2. Abdurrahman bin Hasan, Tafsir alMubin, (Riyadh: Dar Tadmir, 1429 H), $4 / 200$.

3. Abdul Kadir Maghribi, Tafsir Juz Tabaraka, (Kairo: Matba'ah Amirah, 1947), 27.

4. Abi Su'ud, Tafsir Irsyad 'Aqlussalim, (Lebanon, Dar Risalah, 2012), 3/56.

5. Al-Bukhari, Shahih al-Bukhari, (Damaskus: Dar Ibnu Katsir, 2002) dalam kitab cerita para nabi, bab. informasi tentang bani israil, hadis no. 3455

6. Fairuz Abadi, Qamus Muhit, (libanon: Muassasah al-Risalah, 2005). huruf sin hal. 781.

7. Lajnah, Ensiklopedia Ilmu Siyasah, (Kuwait: Univ Kuwait, 2010), hal. 102.

8. Imam Baidhowi, Anwarut Tanzil wa Asraru al-Takwil, (Beirut: Dar shadir, 2001), 2/994.

9. Imam Abi Su'ud, Tafsir Irsyad 'Aqlussalim, (Lebanon: Dar Risalah, 2012), 2/27.

10. Shafiyyurrahman Mubarak Furi, Ahzab Siyasiyah fi al-Islam, (Kairo: Dar Subul Mukmininin, 2012), 83.

11. Imam Fakhrurrazi, Tafsir Kabir, (Libanon: Dar al-Fikr, 1981), 159.

12. Ibnu Katsir, Tafsir al-Quran al-'Azim, (Saudi: Dar Thibah, 1999), 25.

13. Muhamad Mutawaly Sa'rawi, Khawatir Al-Quran, (Kairo: El-Akbar Yaum, 2001), 13/445.

14. Muslim ibn Hajjaj al-Qusyairi alNaysaburi, Shahih Muslim, (Saudi: Dar Thibah, 2006), 2865.

15. Muhammad Mahmud, Silatul Arham, Waahkamul Khas biha fi Fiqhil Islami, (Libanon: Dar Basyair Islamiyah, 2011), 84 .

16. Sayyid Muhammad Azzubaidi, Qamus Taj 'Urus, (Kuwait: Hukumah Kuwait, 1965) jilid. 16 huruf sin, hal. 158.

17. Yovenska, L., and Olan Darmadi. "Karakteristik Pemimpin dalam Islam." Al Imarah: Jurnal
Pemerintahan dan Politik Islam 4.2 (2019): 150-162.

18. Yusuf al-Qaradhawi, Malamih Mujtama' Muslim Kama Nansyuduha (Kairo, Maktabah Wahbah, 2013), 68.

19. Zulfikar, Eko. "Tradisi Halal Bihalal dalam Perspektif Al-Qurân dan Hadis." Jurnal Studi Al-Qur'an 14.2 (2018): 127-150. 